\title{
Stability Analysis of Salt-gradient Solar Pond under External Heat Addition with Different Salts
}

\author{
Abhishek Kumar' ${ }^{1}$ Ranjan Das ${ }^{2}$ \\ ${ }^{1} \mathrm{Ph} . D$. Research Scholar, Indian Institute of Technology Ropar, Rupnagar, Punjab, India - 140001 \\ abhishek.kumar@iitrpr.ac.in \\ ${ }^{2}$ Associate Professor, Indian Institute of Technology Ropar, Rupnagar, Punjab, India - 140001 \\ ranjandas@iitrpr.ac.in
}

\begin{abstract}
This paper is aimed at experimental and numerical analyses of temperature and stability aspects of a salt-gradient solar pond when subjected to external heat addition. A lab-scale setup consisting of a mini cylindrical solar pond was fabricated, and experiments were conducted under simulated radiation using a halogen lamp. External heat addition was provided till nearly attainment of steady-state by circulating electrically-heated water from an insulated storage tank to the solar pond using a copper heat exchanger installed at the lower zone of the pond. A numerical model based on the solution of differential heat balance equations in the gradient zone was also developed to predict the temperature and salinity variation in the pond with time. The model was validated with the experiments conducted on the lab-scale setup using sodium chloride salt. The stability coefficients concerning the upper and lower zones were established for various cases of inlet temperatures and different upper zone thicknesses. The model was further utilized to study the temperature and stability of ponds based on calcium chloride and sodium carbonate salts. A maximum absolute error of 5.94 $\%, 8.82 \%$, and $8.4 \%$ between the experimental and numerical results was observed for inlet temperature of $40{ }^{\circ} \mathrm{C}, 50{ }^{\circ} \mathrm{C}$ and $60{ }^{\circ} \mathrm{C}$ respectively. At upper zone thickness of $0.06 \mathrm{~m}$ and $0.08 \mathrm{~m}$, the maximum deviations between experimental and numerical results were observed to be $8.97 \%$ and $7.06 \%$, respectively. The maximum temperatures of $37.16{ }^{\circ} \mathrm{C}, 45.02{ }^{\circ} \mathrm{C}$ and $52.89{ }^{\circ} \mathrm{C}$ were achieved for $\mathrm{CaCl}_{2}$ at inlet temperatures of $40{ }^{\circ} \mathrm{C}, 50^{\circ} \mathrm{C}$ and $60{ }^{\circ} \mathrm{C}$, respectively. The corresponding maximum temperatures achieved for $\mathrm{Na}_{2} \mathrm{Co}_{3}$ were $37.03{ }^{\circ} \mathrm{C}, 44.86{ }^{\circ} \mathrm{C}$ and $52.7^{\circ} \mathrm{C}$. For the same set of parameters the highest temperatures $\left(37.5^{\circ} \mathrm{C}, 45.6{ }^{\circ} \mathrm{C}\right.$ and $\left.53.7{ }^{\circ} \mathrm{C}\right)$ were recorded using $\mathrm{NaCl}$ salt.
\end{abstract}

Keywords: solar pond, stability, different salts, zonal thickness, external heat addition, hybrid system

\section{Introduction}

Salt gradient solar ponds are typical solar energy collectors that collect and store solar energy falling on its top layers in the form of heat within high-density layers located at the bottom region. The heat is trapped inside the lower layers of the pond by means of halocline prevailing in the gradient zone (GZ) separating the upper zone (UZ) and the storage zone (SZ) of the pond. Solar ponds have been utilized in various applications such as desalination [1], thermoelectric power generation [2], [3], room-heating [4], and more.

One of the major concerns regarding solar ponds is their low thermal efficiency. Consequently, this technology is not finding much use in industrial and commercial applications compared to other solar thermal technologies. Various techniques have been used by researchers to enhance the thermal performance and stability of solar ponds. Heat extraction from multiple zones of the solar pond rather than only the SZ is a novel technique of efficiency improvement that was proposed by Andrews and Akbarzadeh [5]. It was revealed from the study that heat extraction from GZ along with the SZ could potentially increase the system's thermal performance by $50 \%$. The use of nanofluids in the SZ of a two-layered solar pond was demonstrated by Al-Nimr and Al-Dafaie [6], where the UZ was made up of mineral oil instead of saline water that created a transparent GZ. They observed substantial increase in the thermal efficiency of nanofluids-based pond compared to the conventional salt gradient solar pond. Wang et al. [7] studied the effect of different porous materials added to the SZ. Their study concluded that the addition of coal cinder to SZ of the solar pond significantly enhances its thermal performance. Kumar et al. [8] optimized the thickness of three zones of a salt gradient solar pond based on different climatic factors using a binary-coded genetic algorithm. Verma and Das [9] optimized the wall profile and cross-sectional shape for the thermal performance enhancement of solar pond. Their study revealed that the vertical wall profile is the 
most optimum for any given cross-section. Verma and Das [10] further proposed that the heat extraction could be performed from the GZ, NZ, and the ground beneath. In their study, they optimized this triple zone extraction based pond for the condition of constant volume using analytical solutions. Tian et al. [11] proposed the use of an external magnetic field to enhance the stability of the solar pond. Their study revealed an increase in heat storage capacity and stability of the pond when subjected to an external magnetic field. Moreover, a reduction of interface erosion was also observed.

Recently, researchers have suggested hybrid solar pond systems where heat from another type of solar collector is added to SZ of the solar pond. The inherent ability of solar ponds to store heat is utilized in this manner to store excess heat from solar collectors, which otherwise requires separate thermal storage. Ganguly et al. [12] studied the evacuated tube solar collector and solar pond-based hybrid system. They observed that in such a system, optimising the heat extraction and heat addition is important as the pond's temperature varies based on the amount of heat extraction in hybrid systems. In another study, Ganguly et al. [13] studied the increase in the thermal mass of a solar pond through external heat addition. Their study revealed that the heat added to the SZ could significantly increase the efficiency of the solar pond and solar collector based hybrid system.

The stability of a salt gradient solar pond is another vital aspect that needs to be ensured for its optimal working. Giestas et al. [14] studied the effect of radiation absorption on the stability of salt gradient solar ponds. Dah et al. [15] experimentally and numerically studied the stability of a mini solar pond subjected to heat extraction from the GZ along with the SZ. Montala et al. [16] analysed the stability of an industrial solar pond using two methods based on the stratification principle. Their study revealed that the boundaries of a salt gradient solar pond are the primary source of instability in such systems. Verma and Das [17] studied the stability of a solar pond with heat extraction from the ground beneath the solar pond.

It is eventually found that the effect of heat addition temperature and the UZ thickness on the stability behaviour of commonly used salts is not clearly understood. Therefore, in this work, a numerical model is developed to study the temperature development and salt diffusion occurring in the solar pond. Further, the pond was experimentally tested for stability with different salts at different heat inlet temperatures (Tinlet), and different layer thicknesses of the UZ. The lab scale setup fabricated for performing the experiments is discussed in the subsequent section.

\section{Experimental Setup}

As shown in Fig. 1, the experimental setup consists of a mini cylindrical solar pond constructed with a diameter of $0.36 \mathrm{~m}$ and a height of $0.5 \mathrm{~m}$. The inner surface of the pond is painted black to absorb the maximum amount of radiation. The lengths of the $\mathrm{SZ}$ and the GZ were kept as $0.12 \mathrm{~m}$ and $0.2 \mathrm{~m}$, respectively. The length of the UZ was varied from $0.06 \mathrm{~m}$ to $0.08 \mathrm{~m}$. A $500 \mathrm{~W}$ halogen lamp is utilized to simulate the intensity of the solar radiation. The lamp is placed at a distance of $0.3 \mathrm{~m}$ from the top surface of the cylindrical pond. Pyra made $300 \mathrm{~V}$ radiation sensor was utilized to measure the intensity of the radiation falling on the top surface of the pond. A Plexiglas sheet is placed between the halogen lamp and the pond to filter the ultraviolet radiation below $300 \mathrm{~nm}$ and infrared rays above 25000 $\mathrm{nm}$ [18]. This is done in order to avoid the overheating of the UZ and the GZ [18]. Insulation thickness, xins $=0.01 \mathrm{~m}$ was adopted for the entire analysis. 


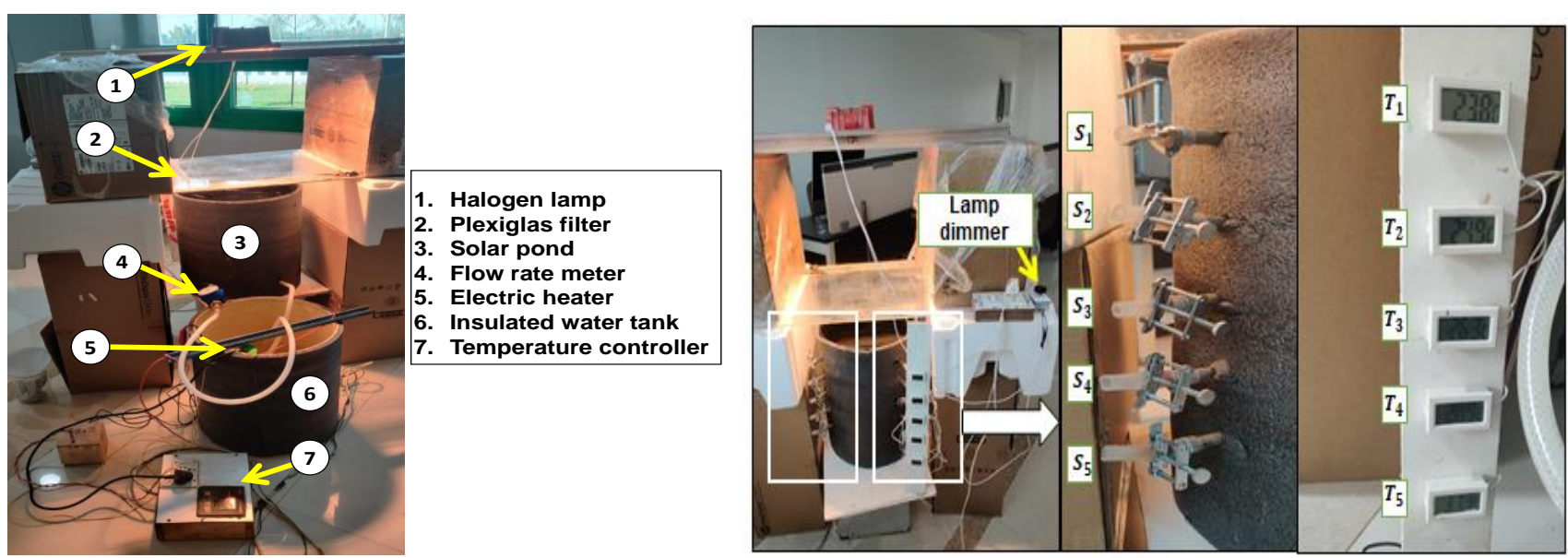

Fig. 1: Details of the experimental setup

To measure the temperature, five digital thermometers are installed at a uniform gap of $0.07 \mathrm{~m}$. Hot water was circulated through a copper heat exchanger installed in the SZ. The diameter of the copper pipes was $0.0127 \mathrm{~m}$. Hot water was stored in a separate thermal storage tank. To heat the water, a $2 \mathrm{~kW}$ electric heater was used. The hot water temperature was maintained constant within accuracy of $\pm 1 \mathrm{oC}$ using a temperature controller and was circulated to the heat exchanger using a $12 \mathrm{~V}$ DC hot water pump. A flow meter was also installed to measure the water flow through the heat exchanger. The temperatures and salinities values were recorded at certain time intervals from five locations as shown in Fig. 1. The salinity was measured in parts per thousand (\%o) using a refractometer with a working range of 0-100 \%o. To measure the salinity above this range, the saltwater sample was diluted using de-ionized water to bring the salinity of the mixture in the working range.

\section{Numerical model}

The general equation for a layer at the $G Z$ can be written as follows [4],

$$
\frac{\partial}{\partial x}\left(k \frac{\partial \theta}{\partial x}\right) d x-\frac{\partial}{\partial x}\left[I\left\{\alpha-\beta \ln \left(x+x_{U}\right)\right\}\right] d x=\frac{\partial}{\partial t}\left(\rho c_{p} \theta\right) d x
$$

Here, $k$ is the thermal conductivity of salt water in $\mathrm{W} /(\mathrm{m} . \mathrm{K}), \theta$ is the excess temperature in ${ }^{\circ} \mathrm{C}, x$ is the distance measured from the $U Z-G Z$ interface in downward direction, $t$ is time in s, $I$ is the radiation intensity in $\mathrm{W} / \mathrm{m}^{2}, \alpha, \beta$ are the constants used in Rabl and Nielsen's equation [19], $\rho$ and $c_{p}$ is the density and specific heat of salt water in $\mathrm{kg} / \mathrm{m}^{3} \mathrm{and} \mathrm{J} / \mathrm{kg}$, respectively. Boundary and initial conditions for Eq. (1) are mentioned below,

$$
U Z \text { remains at ambient temperature }: T(0, t)=T_{a} \text { or } \theta(0, t)=0
$$

$S Z$ energy balance:

$$
\begin{gathered}
I A\left\{\alpha-\beta_{i} \ln \left(x_{G}+x_{U}\right)\right\}-k A\left(\frac{\partial \theta}{\partial x}\right)_{x=x_{G}}+\dot{m} c_{p}\left(\theta_{\text {inlet }}-\theta_{x=x_{G}}\right)=\frac{\partial}{\partial t}\left(\rho A x_{L} c_{p} \theta_{x=x_{G}}\right) \\
T(x, 0)=T_{a} \text { or } \theta(x, 0)=0
\end{gathered}
$$

where, $T$ and $T_{a}$ respectively denote local and ambient temperatures, respectively. Above equation is solved using an implicit finite difference scheme with backward time and central space discretization. Here, $k=0.6 \mathrm{~W} /(\mathrm{m} . \mathrm{K})[20]$, $x_{U}, x_{G}$ and $x_{L}$ are the thickness of $U Z, G Z$ and $S Z$, respectively and $A$ is the area of the pond. While discretizing, the space (central differencing) and time steps are taken as, $d x=x_{G} / 5$ and $d t=3600 \mathrm{~s}=1$ hour, respectively. The general equation for salt diffusion is given as follows [17], 


$$
\frac{\partial}{\partial x}\left(D \frac{\partial c}{\partial x}\right)=\frac{\partial c}{\partial t} ; D=D_{1}+D_{2} \theta
$$

Boundary and initial conditions for Eq. (3) are written below,

$$
-D\left(\frac{\partial c}{\partial x}\right)_{x=0}=x_{U}\left(\frac{\partial c}{\partial t}\right)_{x=0} ; D\left(\frac{\partial c}{\partial x}\right)_{x=x_{G}}=x_{L}\left(\frac{\partial c}{\partial t}\right)_{x=x_{G}} ; c(x, 0)=100 x \%
$$

$D$ in Eq. (3) is the diffusion coefficient and $D_{1}$ and $D_{2}$ are the constants used for its calculation. In Eqs. (3 and 4 ), $c$ is the salinity percentage. The uncertainty analysis is discussed in the subsequent section.

\section{Uncertainty analysis}

In this work, the measurement uncertainties in temperature, salinity, mass flow rate and radiation intensity measurements are accounted for. The uncertainties in temperature and radiation measurements are calculated by first computing the average of three replicates [21] as,

$$
T_{\text {avg }}=\frac{T_{1}+T_{2}+T_{3}}{3} ; I_{\text {avg }}=\frac{I_{1}+I_{2}+I_{3}}{3}
$$
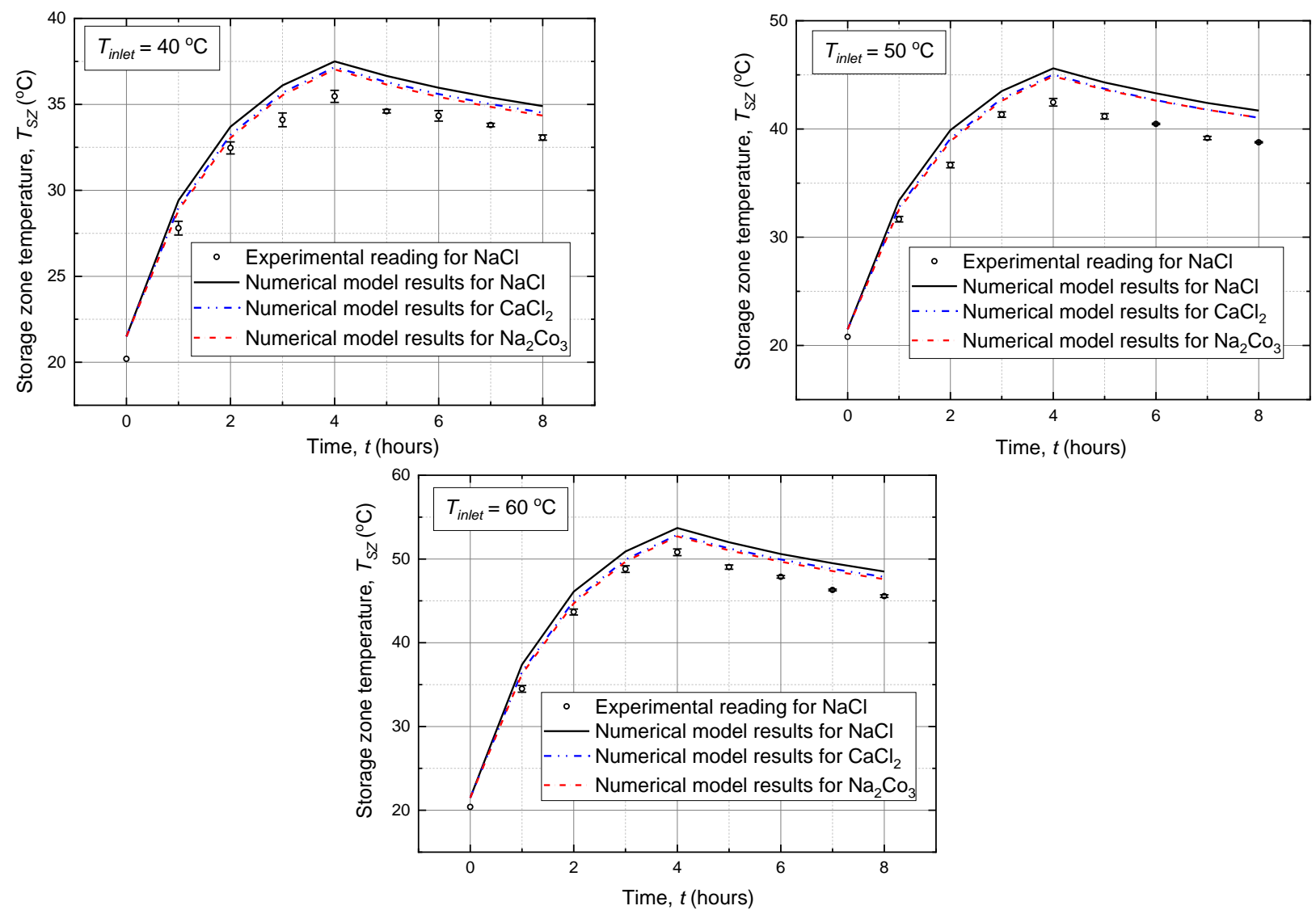

Fig. 2: Experimental and numerical results for different Tinlet; $\mathrm{xU}=0.07 \mathrm{~m}, \mathrm{xG}=0.2 \mathrm{~m}, \mathrm{xL}=0.12 \mathrm{~m}, \mathrm{~d}=0.36 \mathrm{~m}, \dot{m}=$ $0.0095 \mathrm{~kg} / \mathrm{s}$, xins. $=0.01 \mathrm{~m}$

Thereafter uncertainties are calculated as follow [21], 


$$
\begin{aligned}
& u_{T}=\left[\sum_{n=1}^{3}\left(\frac{\partial T_{a v g}}{\partial T_{n}} \times u_{T_{n}}\right)^{2}\right]^{1 / 2}=\left[3 \times\left(\frac{1}{3} \times 0.05\right)^{2}\right]^{1 / 2}=0.0289{ }^{\circ} \mathrm{C} \\
& u_{I}=\left[\sum_{n=1}^{3}\left(\frac{\partial I_{a v g}}{\partial I_{n}} \times u_{I_{n}}\right)^{2}\right]^{1 / 2}=\left[3 \times\left(\frac{1}{3} \times 0.5\right)^{2}\right]^{1 / 2}=0.2887 \mathrm{~W} / \mathrm{m}^{2}
\end{aligned}
$$

where, $u_{T_{1}}=u_{T_{2}}=u_{T_{3}}=0.05{ }^{\circ} \mathrm{C}$ and $u_{I_{1}}=u_{I_{2}}=u_{I_{3}}=0.5 \mathrm{~W} / \mathrm{m}^{2}$ are the absolute uncertainties in the direct measurement of the temperature and solar radiation, respectively. The uncertainty in digital measurements is taken as half of the least count of the measuring device. For analogue devices, the uncertainty is taken equal to the least count of the device. The uncertainty in mass flow rate measurement is calculated as follows [21],

$$
u_{\dot{m}}=\left[\sum_{n=1}^{10}\left(\frac{\partial \dot{m}_{\text {avg }}}{\partial \dot{m}_{n}} \times u_{\dot{m}}\right)^{2}\right]^{1 / 2}=\left[10 \times\left\{\frac{1}{10} \times\left(\frac{0.1}{10.437}\right)\right\}^{2}\right]^{1 / 2}=0.003 \mathrm{~kg} / \mathrm{s} ; \dot{m}_{\text {avg }}=\frac{\dot{m}_{1}+\dot{m}_{2} \ldots+\dot{m}_{10}}{10}
$$

Here, 10.437 seconds is the average time measured experimentally for $0.1 \mathrm{~kg}$ water to flow in the heat exchanger. The uncertainty in salt refractometer measurement is the least count i.e., $1 \%$. The results and discussions are given in the following section.

\section{Results and Discussion}

Experiments were conducted on the lab scale setup discussed in Section 2. Three sets of experiments were conducted by varying the temperature of the hot water entering the copper exchanger of the SZ. Figure 2 shows the result of SZ temperatures achieved at Tinlet of $40 \mathrm{oC}, 50 \mathrm{oC}$, and $60 \mathrm{oC}$ for 4 hours heating and 4 hours observation period. The experimental and numerical results for the $\mathrm{NaCl}$ salt are compared in Fig. 2. For Tinlet of $40 \mathrm{oC}, 50 \mathrm{oC}$, and $60 \mathrm{oC}$, maximum absolute errors of $5.94 \%, 8.82 \%$, and $8.4 \%$, respectively were observed between the experimental and numerical results.

The model was utilized to analyse the stability of the pond system under external heat addition for different salts. Two commonly used salts in salt gradient solar ponds apart from $\mathrm{NaCl}$ are $\mathrm{CaCl} 2$ and $\mathrm{Na} 2 \mathrm{Co} 3$. The correlations used for obtaining the density, thermal conductivity and specific heat are as follow [22],

$$
\begin{array}{ll}
\rho_{\mathrm{CaCl}_{2}}=0.085 c^{2}+7.4853 c+999.78 & \rho_{\mathrm{Na}_{2} \mathrm{CO}_{3}}=0.045 c^{2}+10.71 c+1001.1 \\
c_{p, \mathrm{CaCl}_{2}}=0.4547 c^{2}-68.818 c+4225.2 ; & c_{p, \mathrm{Na}_{2} \mathrm{Co}_{3}}=0.9917 c^{2}-48.728 c+4190.2 \\
k=0.553-0.0000813 c+0.0008(T-20) & k=0.553-0.0000813 c+0.0008(T-20)
\end{array}
$$

The temperature achieved numerically in the $\mathrm{SZ}$ of the pond for $\mathrm{CaCl} 2$ and $\mathrm{Na} 2 \mathrm{Co} 3$ salts is also given in Fig 2. The maximum temperatures of $37.16 \mathrm{oC}, 45.02 \mathrm{oC}$ and $52.89 \mathrm{oC}$ were achieved for $\mathrm{CaCl} 2$ for Tinlet of $40 \mathrm{oC}, 50 \mathrm{oC}$, and 60 $\mathrm{oC}$, respectively. The corresponding maximum temperatures achieved for $\mathrm{Na} 2 \mathrm{Co} 3$ were $37.03 \mathrm{oC}, 44.86 \mathrm{oC}$ and $52.7 \mathrm{oC}$. For the same set of parameters the highest temperatures were achieved using $\mathrm{NaCl}$ salt $(37.5 \mathrm{oC}, 45.6 \mathrm{oC}$ and $53.7 \mathrm{oC})$.

Figure 3 presents the variation of SZ temperature at various times by varying $\mathrm{xU}$ from $0.06 \mathrm{~m}$ to $0.08 \mathrm{~m}$ at Tinlet of 40 oC. Maximum absolute percentage errors of $8.97 \%$, and $7.06 \%$ between the experimental and numerical results were observed for $\mathrm{xU}=0.06 \mathrm{~m}$ and $0.08 \mathrm{~m}$, respectively. Further, maximum temperatures of $37.17 \mathrm{oC}$ and $37.15 \mathrm{oC}$ were achieved for $\mathrm{CaCl} 2$ corresponding to $\mathrm{xU}=0.06 \mathrm{~m}$ and $0.08 \mathrm{~m}$, respectively. The corresponding maximum temperatures achieved for $\mathrm{Na} 2 \mathrm{Co} 3$ were $37.04 \mathrm{oC}$ and $37.02 \mathrm{oC}$. However, for the same set of parameters, the highest temperatures were achieved using $\mathrm{NaCl}$ salt $(37.5 \mathrm{oC}$ and $37.4 \mathrm{oC}$ ). It is highlighted that at large $\mathrm{xU}$ values, due to absorption of radiation, relatively lower temperatures were recorded, although the differences are quite marginal for this work. 
The salinity measurements were experimentally recorded for $\mathrm{NaCl}$ salt during the period of 8 hours are given in Table 1. The salinities were measured at an interval of 1 hour during the heating period of 4 hours and observation period of 4 hours each. The stability coefficients for the surface and bottom layers of the pond were calculated using the salinity and temperature data. The stability coefficient is defined as [23],

$$
\xi=\frac{d S}{d x} / \frac{d T}{d x}
$$

The $\xi$ values calculated for different Tinlet under varying $\mathrm{xU}$ are given in Fig. 4. It can be observed that $\xi$ values are higher for lower Tinlet. This is because at higher Tinlet, the lower layers get heated up and the denominator part of Eq. 10 increases. Due to this the stability coefficient gives lower values at lower Tinlet.
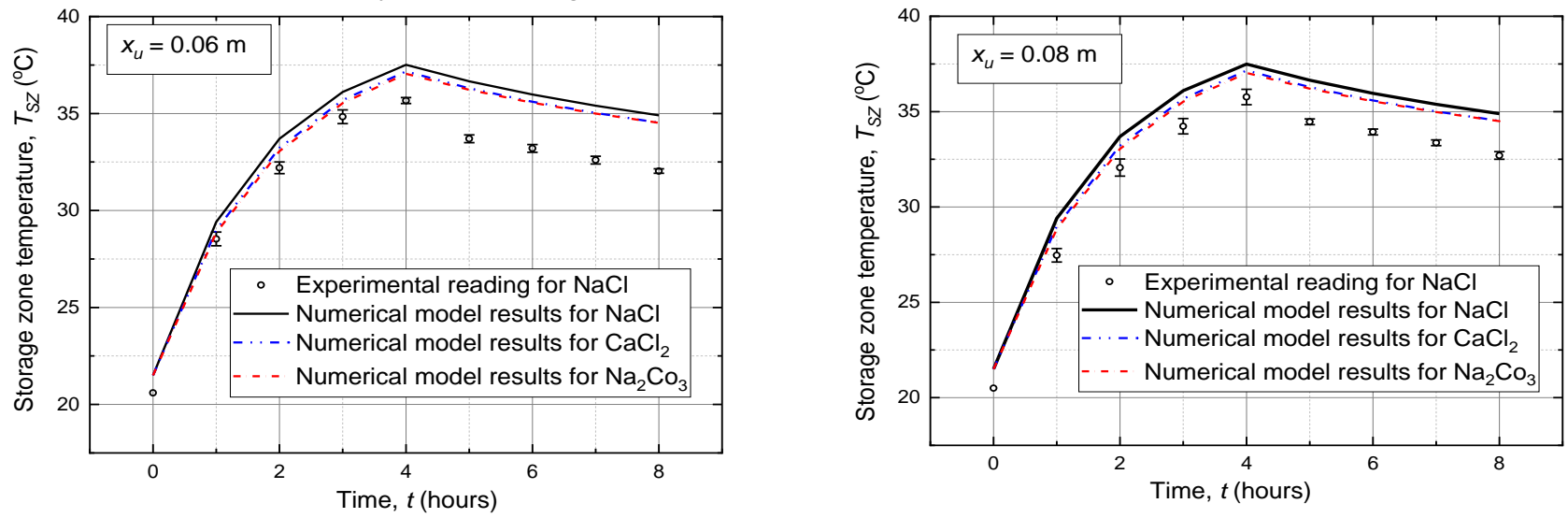

Fig. 3: Experimental and numerical results for different upper zone thicknesses, Tinlet $=40 \mathrm{oC} x \mathrm{x}=0.2 \mathrm{~m}, \mathrm{xL}=0.12 \mathrm{~m}, \mathrm{~d}=$ $0.36 \mathrm{~m}, \dot{m}=0.0095 \mathrm{~kg} / \mathrm{s}$, xins $=0.01 \mathrm{~m}$

Table 1: Salinities recorded while performing experiment corresponding to various cases; $\mathrm{xG}=0.2 \mathrm{~m}, \mathrm{xL}=0.12 \mathrm{~m}, \mathrm{~d}=0.36 \mathrm{~m}, \dot{m}=$ $0.0095 \mathrm{~kg} / \mathrm{s}$, xins $=0.01 \mathrm{~m}$

\begin{tabular}{|c|c|c|c|c|c|c|c|c|}
\hline Salinity & $t=1$ hour & $t=2$ hours & $t=3$ hours & $t=4$ hours & $t=5$ hours & $t=6$ hours & $t=7$ hours & $t=8$ hours \\
\hline \multicolumn{9}{|c|}{$T_{\text {inlet }}=40^{\circ} \mathrm{C}, x_{U}=0.07 \mathrm{~m}$} \\
\hline S1 (\%) & 0.5 & 0.5 & 0.5 & 0.5 & 0.5 & 0.5 & 0.6 & 0.6 \\
\hline$S 2(\%)$ & 57 & 57 & 57 & 57 & 57.2 & 57.3 & 57.5 & 57.8 \\
\hline$S 3(\%)$ & 104 & 104 & 104 & 104 & 104 & 104.2 & 104.2 & 104.4 \\
\hline S4 (\%o) & 149 & 149 & 149 & 149 & 149 & 149 & 149.3 & 149.3 \\
\hline S5 (\%) & 197 & 197 & 197 & 197 & 197 & 197 & 196.8 & 196.5 \\
\hline \multicolumn{9}{|c|}{$T_{\text {inlet }}=50^{\circ} \mathrm{C}, x_{U}=0.07 \mathrm{~m}$} \\
\hline S1 (\%) & 0.2 & 0.2 & 0.2 & 0.2 & 0.2 & 0.2 & 0.3 & 0.3 \\
\hline$S 2(\%)$ & 52 & 52 & 52 & 52 & 52 & 52 & 52.3 & 52.5 \\
\hline$S 3(\%)$ & 103 & 103 & 103 & 103 & 103 & 103 & 103.2 & 103.4 \\
\hline$S 4(\%)$ & 155 & 155 & 155 & 155 & 155 & 155 & 155.2 & 155.5 \\
\hline S5 (\%) & 199 & 199 & 199 & 199 & 199 & 199 & 199 & 198 \\
\hline \multicolumn{9}{|c|}{$T_{\text {inlet }}=60^{\circ} \mathrm{C}, x_{U}=0.07 \mathrm{~m}$} \\
\hline S1 (\%) & 0.3 & 0.3 & 0.3 & 0.3 & 0.3 & 0.3 & 0.4 & 0.4 \\
\hline$S 2(\%)$ & 53 & 53 & 53 & 53 & 53 & 53.2 & 53.3 & 53.5 \\
\hline$S 3(\%)$ & 108 & 108 & 108 & 108 & 108 & 108 & 108.2 & 108.5 \\
\hline S4 (\%o) & 159 & 159 & 159 & 159 & 159.2 & 159.3 & 159.5 & 159.8 \\
\hline S5 (\%) & 198 & 198 & 198 & 198 & 198 & 197.8 & 197.5 & 197.5 \\
\hline \multicolumn{9}{|c|}{$x_{U}=0.06 \mathrm{~m}, T_{\text {inlet }}=40^{\circ} \mathrm{C}$} \\
\hline S1 (\%) & 0.3 & 0.3 & 0.3 & 0.3 & 0.3 & 0.4 & 0.4 & 0.4 \\
\hline
\end{tabular}




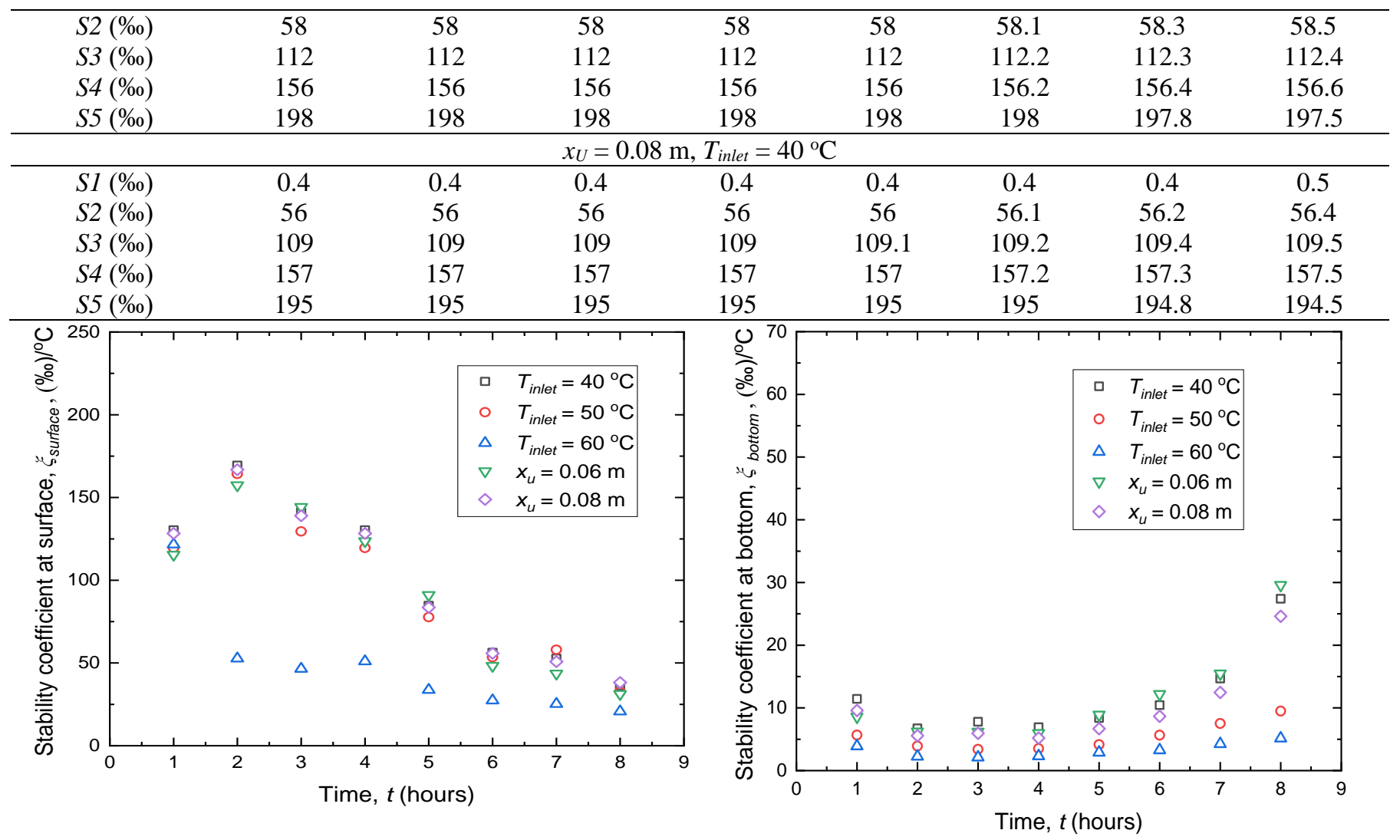

Fig. 4: Stability coefficients calculated for surface and bottom; $x G=0.2 \mathrm{~m}, \mathrm{xL}=0.12 \mathrm{~m}, \mathrm{~d}=0.36 \mathrm{~m}, \dot{m}=0.0095 \mathrm{~kg} / \mathrm{s}, \mathrm{xins}$ $=0.01 \mathrm{~m}$

\section{Conclusions}

In this work the thermal behaviour and stability of a salt gradient solar pond were analysed for a lab scale setup. A numerical model was developed based on the solution of differential heat balance equations in the $G Z$. The temperatures achieved in the $S Z$ for different salts under different sets of parameters were analysed. The stability coefficients were also computed for various parametric combinations. Maximum temperatures of $37.16^{\circ} \mathrm{C}, 45.02{ }^{\circ} \mathrm{C}$ and $52.89{ }^{\circ} \mathrm{C}$ were achieved for $\mathrm{CaCl}_{2}$ at $T_{\text {inlet }}$ of $40{ }^{\circ} \mathrm{C}, 50{ }^{\circ} \mathrm{C}$, and $60{ }^{\circ} \mathrm{C}$, respectively and $x_{U}=0.07 \mathrm{~m}$. The corresponding maximum temperatures achieved for $\mathrm{Na}_{2} \mathrm{Co}_{3}$ were $37.03{ }^{\circ} \mathrm{C}, 44.86{ }^{\circ} \mathrm{C}$ and $52.7{ }^{\circ} \mathrm{C}$. The maximum temperatures of $37.17{ }^{\circ} \mathrm{C}$ and $37.15{ }^{\circ} \mathrm{C}$ were achieved for $\mathrm{CaCl}_{2}$ with $x_{U}=0.06 \mathrm{~m}$ and $0.08 \mathrm{~m}$, respectively at $T_{\text {inlet }}$ of $40{ }^{\circ} \mathrm{C}$. The corresponding maximum temperatures achieved for $\mathrm{Na}_{2} \mathrm{Co}_{3}$ were $37.04{ }^{\circ} \mathrm{C}$ and $37.02{ }^{\circ} \mathrm{C}$. For the same set of parameters in all of the cases considered, the highest temperatures were achieved using $\mathrm{NaCl}$ salt $\left(37.5{ }^{\circ} \mathrm{C}, 45.6{ }^{\circ} \mathrm{C}, 53.7^{\circ} \mathrm{C}, 37.5{ }^{\circ} \mathrm{C}\right.$ and $\left.37.4{ }^{\circ} \mathrm{C}\right)$. The stability coefficients were found relatively lower at higher inlet temperatures compared to those existing at low inlet temperature of the heat exchanger. 


\section{References}

[1] H. Lu, J. C. Walton, and A. H. P. Swift, "Desalination coupled with salinity-gradient solar ponds," Desalination, vol. 136, no. 1-3, pp. 13-23, 2001.

[2] S. Tundee, N. Sirhajong, N. Srihajong, R. Singh, and A. Akbarzadeh, "Combined thermosyphon and thermoelectric modules for power generation from salinity gradient solar ponds," in International Solar Energy Society Conference Proceedings, Jan. 2010, no. October, pp. 1-8.

[3] B. M. Ziapour, M. Saadat, V. Palideh, and S. Afzal, "Power generation enhancement in a salinity-gradient solar pond power plant using thermoelectric generator," Energy Convers. Manag., vol. 136, pp. 283-293, 2017.

[4] S. Verma and R. Das, "Transient study of a solar pond under heat extraction from non-convective and lower convective zones considering finite effectiveness of exchangers," Sol. Energy, vol. 223, pp. 437-448, 2021.

[5] J. Andrews and A. Akbarzadeh, "Enhancing the thermal efficiency of solar ponds by extracting heat from the gradient layer," Sol. Energy, vol. 78, no. 6, pp. 704-716, 2005.

[6] M. A. Al-Nimr and A. M. A. Al-Dafaie, "Using nanofluids in enhancing the performance of a novel two-layer solar pond," Energy, vol. 68, pp. 318-326, 2014.

[7] H. Wang, J. Zou, J. L. Cortina, and J. Kizito, "Experimental and theoretical study on temperature distribution of adding coal cinder to bottom of salt gradient solar pond," Sol. Energy, vol. 110, pp. 756-767, 2014.

[8] A. Kumar, K. Singh, S. Verma, and R. Das, "Inverse prediction and optimization analysis of a solar pond powering a thermoelectric generator," Sol. Energy, vol. 169, pp. 658-672, 2018.

[9] S. Verma and R. Das, "Wall profile optimisation of a salt gradient solar pond using a generalized model," Sol. Energy, vol. 184, pp. 356-371, 2019.

[10] S. Verma and R. Das, "Concept of triple heat exchanger-assisted solar pond through an improved analytical model," $J$. Sol. Energy Eng., vol. 141, no. 5, p. 51003, 2019.

[11] D. Tian, Z. G. Qu, J. F. Zhang, and Q. L. Ren, "Enhancement of solar pond stability performance using an external magnetic field," Energy Convers. Manag., vol. 243, p. 114427, 2021.

[12] S. Ganguly, R. Jain, A. Date, and A. Akbarzadeh, "On the addition of heat to solar pond from external sources," Sol. Energy, vol. 144, pp. 111-116, 2017.

[13] S. Ganguly, A. Date, and A. Akbarzadeh, "On increasing the thermal mass of a salinity gradient solar pond with external heat addition: A transient study," Energy, vol. 168, pp. 43-56, 2019.

[14] M. Giestas, H. Pina, and A. Joyce, "The influence of radiation absorption on solar pond stability," Int. J. Heat Mass Transf., vol. 39, no. 18, pp. 3873-3885, 1996.

[15] M. M. Ould Dah, M. Ouni, A. Guizani, and A. Belghith, "The influence of the heat extraction mode on the performance and stability of a mini solar pond," Appl. Energy, vol. 87, no. 10, pp. 3005-3010, 2010.

[16] M. Montalà, J. L. Cortina, A. Akbarzadeh, and C. Valderrama, "Stability analysis of an industrial salinity gradient solar pond," Sol. Energy, vol. 180, pp. 216-225, 2019.

[17] S. Verma and R. Das, "Effect of ground heat extraction on stability and thermal performance of solar ponds considering imperfect heat transfer," Sol. Energy, vol. 198, pp. 596-604, 2020.

[18] M. Ines, P. Paolo, F. Roberto, and S. Mohamed, "Experimental studies on the effect of using phase change material in a salinity-gradient solar pond under a solar simulator," Sol. Energy, vol. 186, pp. 335-346, 2019.

[19] A. Rabl and C. E. Nielsen, "Solar ponds for space heating," Sol. Energy, vol. 17, no. 1, pp. 1-12, 1975.

[20] M. Husain, P. S. Patil, S. R. Patil, and S. K. Samdarshi, "Optimum size of non-convective zone for improved thermal performance of salt gradient solar pond," Sol. Energy, vol. 74, no. 5, pp. 429-436, 2003.

[21] R. Goswami and R. Das, "Waste heat recovery from a biomass heat engine for thermoelectric power generation using two-phase thermosyphons," Renew. Energy, vol. 148, pp. 1280-1291, 2020.

[22] M. Berkani, H. Sissaoui, A. Abdelli, M. Kermiche, and G. Barker-Read, "Comparison of three solar ponds with different salts through bi-dimensional modeling," Sol. Energy, vol. 116, pp. 56-68, 2015.

[23] M. Mazidi, M. H. Shojaeefard, M. S. Mazidi, and H. Shojaeefard, "Two-dimensional modeling of a salt-gradient solar pond with wall shading effect and thermo-physical properties dependent on temperature and concentration," J. Therm. Sci., vol. 20, no. 4, pp. 362-370, 2011. 
112-9 